Rakenteiden Mekaniikka (Journal of Structural Mechanics)

Vol. 52, No. 4, 2019, pp. 222-235

http://rakenteidenmekaniikka.journal.fi/index

https://doi.org/10.23998/rm.76267

(C) 2019 The Authors

Open access under license CC BY 4.0

\title{
Bonded CFRP to high strength steels
}

\author{
Mohsen Amraei ${ }^{1}$, Lingjia Zong, Antti Ahola and Timo Björk
}

Summary. Research on the bond performance of CFRP-strengthened steel have been done for the past years, but it has mainly focused on lower grades of steel. The performance of the bond between ultra-high modulus (UHM) CFRP and high/ultra-high strength steel (HSS/UHSS) is investigated in this paper. A series of experiments have been conducted, with single/double sidestrengthened (SSS/DSS) HSS/UHSS with CFRP laminates using Araldite adhesive. It was found that strengthening up to the ultimate strength of the DSS specimens is feasible. However, debonding happens at the ultimate strength of SSS specimens.

Keywords: CFRP strengthening, ultra-high strength steel, bond performance

Received 31 October 2018. Accepted 2 October 2019. Published online 31 December 2019.

\section{Introduction}

Carbon Fiber Reinforced Polymers (CFRP) have been widely used to strengthen concrete structures for decades. Significant results have been achieved in retrofitting aged or damaged building structures. However, the research done for applications of CFRP on metallic structures is limited. Some field available applications of CFRP includes strengthening cast iron, steel and aluminium structures. Strengthening with CFRP plate is conducted on several existing bridge projects to reduce the stress and increase fatigue life of steel girders (Zhao et al., 2014). The available research on strengthening steel structures using CFRPs is focused on mild steels with a very limited work on high strength steels (HSS) up to the grade 690 (Amraei et al., 2017), and no work is done on ultra-high strength steels (UHSS).

The applications of HSS/UHSS are significantly increasing in different engineering sectors such as crane and mobile vehicles, building structures, offshore etc. The combination high strength and low weight is of their desirable characteristics. However,

${ }^{1}$ Corresponding author: mohsen.amraei@monash.edu 
their sensitivity to heat input from welding and post welding treatments which results in decreasing their static capacity, alongside with fatigue life reduction of welded details reduces their benefits. The strengthening of welded HSS/UHSS using CFRP can potentially reduce stresses of the weldment and consequently increasing the fatigue life. However, due to their higher load carrying capacities, HSS/UHSS undergo higher stress ranges in which it also creates higher shear stress in the bond between the steel substrate and the CFRP, which accordingly rises concerns about debonding.

The scope of this paper is to investigate the bond relation between CFRP and HSS/UHSS through laboratory experiments. Literature review on the background of CFRP laminates, properties of Araldite adhesive and UHSS are done to fill the gap of knowledge.

The adhesive used is Araldite adhesive, which is known to be the strongest adhesive for industry purpose (Wu et al., 2012). The tensile strength for steel and CFRP laminates of each specimen are to be determined, with the failure loads obtained by experiments. Ultra-high modulus (UHM) CFRP laminates were used in the experiment and results are discussed.

At first, a study of the available literature about bond between steel and CFRP is presented with the emphasize on both behavior and strength of the bond. Available bond models and load-slip relationships are presented. Following that, a series of tests on both single side and double side strengthened (SSS-DSS) UHSS using UHM CFRP is presented. The results show that strengthening higher grades of steel with CFRP is feasible.

\section{Bond behaviour}

\section{Failure mode}

According to Yang et al., failure mode of CFRP-to-steel bonded joints is associated with (i) the properties of the adhesive; (ii) the adhesive layer thickness; (iii) the stiffness of CFRP composites; and (iv) the bond length (Yang et al., 2017). Some other parameters that might affect the failure mode include environmental effects, temperature, strain rate etc.

Failure mode in CFRP bonded double-lap joint depends on the adhesive thickness and material properties of adhesive and CFRP (Xia and Teng 2005, Yu et al. 2012). A schematic view of 6 typical failure modes is provided in Figure 1. The single-lap joint and double-lap joint specimen tested are observed to be mostly failed by CFRP delamination. It was found that cohesion failure tends to occur for thin adhesives, whereas the failure mode tends to change to delamination of CFRP plates for thick adhesives (Zhao et al., 2014), high strength and ductility adhesive. 


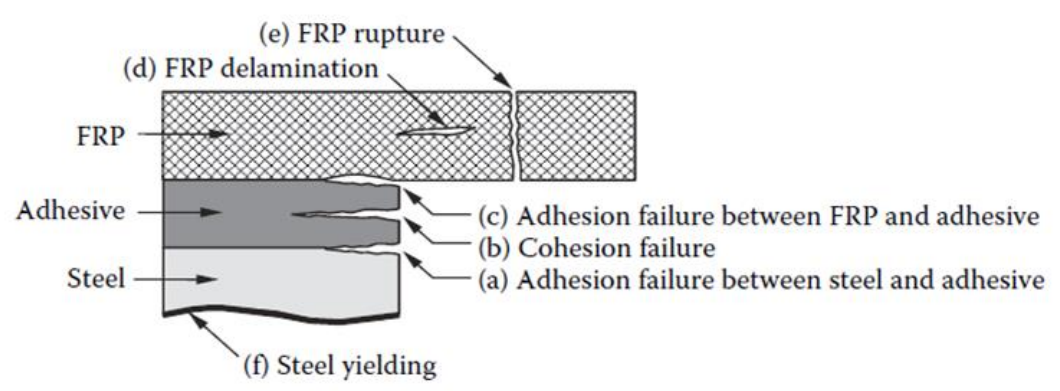

Figure 1. Failure mode schematic view (Zhao and Zhang, 2007).

For Araldite bonded specimens, the bond strength of UHM CFRP-to-adhesive interface and the adhesive-to-steel interface are proven to be stronger than tensile strength of UHM CFRP. According to Wu et al.'s research, CFRP delamination occurs when the bond length is shorter than effective bond length, whereas CFRP rupture occurs when bond length exceeding effective bond length (Wu et al. 2012a).

The failure mode for UHM and NM CFRP differs according to the research done by Xia and Teng (Xia and Teng, 2005) and Wu (Wu et al., 2012a). Wu concludes that for normal modulus CFRP sheets, the failure mode was a combination of steel-adhesive interface failure and CFRP delamination. Whereas for high modulus CFRP sheets, the failure mode was mainly CFRP rupture (Wu et al., 2012a).

\section{Load-displacement curves}

Yu and Teng (Yu et al., 2012) suggested that the ideal failure mode was cohesive failure due to better ductility, which brings in a long plateau on the load-displacement curves. Korayem et al. suggested that the joint can be considered as ductile as a plateau on the load-displacement curve was observed (Korayem et al., 2015). Although FRP delamination failure leads to a much shorter plateau compared to cohesive failure, it can still be considered to be ductile. Therefore, it is also an acceptable failure mode ( $\mathrm{He}$ and Xian, 2016).

\section{Bond slip behaviour}

The interfacial bond-slip behaviour of the CFRP-to-steel interface will present in four distinct stages. In ascending order of slip: elastic; softening; constant; and debonded. The first stage is characterized by an increase in bond stress with slips in an almost linear state until a peak value is reached. Linear softening occurs followed by a constant bond stress lower than maximum value. The last stage corresponds to the complete separation between materials, which is traduced by a zero bond stress transfer (Yang et al., 2017).

Although different CFRP plates lead to different bond strengths (i.e. ultimate loads) of the bonded joints, they have little effect on the bond-slip curves of the bonded interfaces (Yu et al., 2012). The bond-slip curve is shown to have an approximately triangular shape for a linear adhesive but to have an approximately trapezoidal shape for 
a nonlinear adhesive, indicating the necessity of developing different forms of bond-slip models for different adhesives. The shape of the bond-slip curves is only depend on the properties of the adhesive (linear or nonlinear), no matter whether the failure mode is cohesive or delamination. In the study done by He and Xian, few adhesives were analyzed and compared. Bond-slip relationship curves were drawn, as shown in Figure 2 for linear adhesive Ts and for non-linear adhesive Tc (He and Xian, 2016).
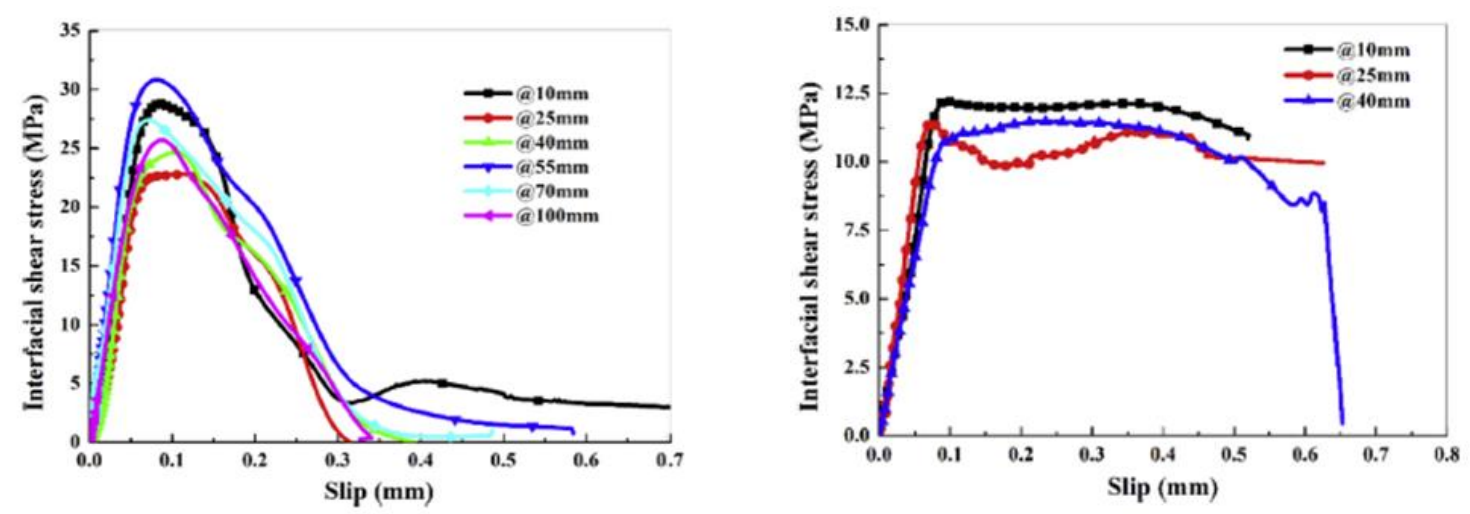

Figure 2. Bond-slip relationship curve for (left) Ts in cohesion failure and (right) Tc in CFRP delamination failure (He and Xian, 2016).

Typically, the strain increases with the load applied. When multiple layers of CFRP are attached to the steel, the benefit of strengthening becomes less significant from layer 4 and beyond (Zhao et al., 2014).

It was observed that the bond-slip curves for CFRP sheet and CFRP plate bonded with linear adhesives are similar. However, it is not the case for non-linear adhesives, where the behaviour distinct.

\section{Bond strength}

\section{Bond slip relationship}

This refers to the relationship between the local shear stress and its corresponding slip along the bond line of the composite joint (Wu et al. 2012a). The relation is independent of geometrics and hence a local bond-slip model may be appropriate to measure bond performance. (Fawzia, Zhao and Al-Mahaidi, 2010)

The bond-slip relationship relates the interfacial shear stress to the interfacial slip of steel structure strengthened by CFRP plate as studied by Xia \& Teng (2005). A local bond-slip relationship is proposed from the experimental results for CFRP sheets bonded to steel structure. The possibility of finding local bond-slip relationship using long bond length (e.g. twice the effective bond length) is strictly related to the consideration of the distribution of slip and bond shear stress along the bond length (Fawzia, Zhao, AlMahaidi, \& Rizkalla, 2004). The bond-slip model is not affected by the bond length beyond the effective bond length. The thickness of adhesive layer has significant effects 
on the bond-slip model, where both initial and maximum slip increase as the adhesive layer thickness increases (Fawzia, Zhao and Al-Mahaidi, 2010). Existing bond slip models are as listed in Table 1 with the following notation: $\tau_{\mathrm{f}}(\mathrm{MPa})$ is the peak interfacial shear stress; $\delta(\mathrm{mm})$ is the local slip; $\delta_{1}(\mathrm{~mm})$ is the relative slip corresponding to the peak interfacial shear stress; $\delta_{2}(\mathrm{~mm})$ is the relative slip when shear stress begins to decrease; $\delta_{\mathrm{f}}(\mathrm{mm})$ is the maximum slip; $\mathrm{f}_{\mathrm{a}}(\mathrm{MPa})$ is the tensile strength of adhesive; $\mathrm{G}_{\mathrm{a}}(\mathrm{MPa})$ is the shear modulus of adhesive; $t_{a}(\mathrm{~mm})$ is the thickness of adhesive; $\mathrm{G}_{\mathrm{a}}(\mathrm{N} / \mathrm{mm})$ is the interfacial fracture energy and $\mathrm{P}_{\mathrm{u}}(\mathrm{kN})$ is the ultimate load.

Table1. Existing bond-slip models.

\begin{tabular}{|c|c|c|c|c|c|c|}
\hline Ref. & Bond-slip model & $\tau_{f}$ & $\delta_{1}$ & $\delta_{2}$ & $\delta_{f}$ & Model type \\
\hline $\begin{array}{l}\text { Teng } \\
\text { (Xia and } \\
\text { Teng, 2005) }\end{array}$ & \multirow{3}{*}{$\begin{array}{c}\tau=\tau_{f} \frac{\delta}{\delta_{1}}, \text { if } \delta \leq \delta_{1} \\
\tau=\tau_{f} \frac{\delta_{f}-\delta}{\delta_{f}-\delta_{1}} \\
\text { if } \delta_{1}<\delta \leq \delta_{f} \\
\tau=0, \text { if } \delta>\delta_{f}\end{array}$} & $0.8 f_{a}$ & $\frac{0.8 t_{a}}{G_{a}} f_{a}$ & N/A & $2 G_{f} / \tau_{f}$ & \multirow{3}{*}{$\begin{array}{c}\text { Bilinear } \\
\text { model }\end{array}$} \\
\hline \multirow{2}{*}{$\begin{array}{l}\text { Fawzia } \\
\text { (Fawzia, } \\
\text { Zhao } \\
\text { and Al- } \\
\text { Mahaidi, } \\
\text { 2010) } \\
\end{array}$} & & \multirow{2}{*}{$f_{a}$} & \multirow{2}{*}{$\frac{t_{a}}{10}$} & \multirow{2}{*}{ N/A } & $\begin{array}{c}\frac{t_{a}}{4} \\
t_{a}=0.1 \sim 0.5 \mathrm{~mm}\end{array}$ & \\
\hline & & & & & $\begin{array}{c}0.125+\frac{t_{a}-0.5}{10} \\
t_{a}=0.5 \sim 1 \mathrm{~mm}\end{array}$ & \\
\hline $\begin{array}{l}\text { Fernando } \\
\text { (Fernando } \\
\text { et al., 2010) }\end{array}$ & $\begin{array}{c}\tau=\tau_{f} \sqrt{\frac{\delta}{\delta_{1}}}, \text { if } \delta \leq \delta_{1} \\
\tau=\tau_{f} \exp \left[-\alpha\left(\frac{\delta}{\delta_{1}}-1\right)\right], \\
\text { if } \delta>\delta_{1} \\
\alpha=\frac{3 \tau_{f} \delta_{1}}{3 G_{f}-2 \tau_{f} \delta_{1}}\end{array}$ & $0.9 f_{a}$ & $0.3\left(\frac{t_{a}}{G_{a}}\right)^{0.65} f_{a}$ & N/A & $2 G_{f} / \tau_{f}$ & $\begin{array}{c}\text { Simplified } \\
\text { model }\end{array}$ \\
\hline $\begin{array}{l}\text { E.Dehghani } \\
\text { (Dehghani } \\
\text { et al., 2012) }\end{array}$ & $\begin{array}{c}\tau=\tau_{f} \frac{\delta}{\delta_{1}}, \text { if } \delta \leq \delta_{1} \\
\tau=\tau_{f}, \text { if } \delta_{1}<\delta \leq \delta_{2} \\
\tau=\tau_{f} \frac{\delta_{f}-\delta}{\delta_{f}-\delta_{2}} \\
\text { if } \delta_{2}<\delta \leq \delta_{f} \\
\tau=0, \text { if } \delta>\delta_{f}\end{array}$ & $0.8 f_{a}$ & $\frac{0.8 t_{a}}{G_{a}} f_{a}$ & $\frac{1}{3} \delta_{f}$ & $\frac{3 G_{f}}{2 \tau_{f}}+\frac{3}{4} \delta_{0}$ & $\begin{array}{c}\text { Trilinear } \\
\text { model }\end{array}$ \\
\hline $\begin{array}{l}\text { He and } \\
\text { Xian }(H e \\
\text { and Xian, } \\
\text { 2017) }\end{array}$ & $\begin{array}{c}\tau=\tau_{f} \frac{\delta}{\delta_{1}}, \text { if } 0<\delta \leq \delta_{1} \\
\tau=\tau_{f} \exp \left[-\beta\left(\delta-\delta_{1}\right)\right] \\
\text { if } \delta>\delta_{1} \\
\beta=\frac{\tau_{f}}{G_{f}-\frac{1}{2} \delta_{1} \tau_{f}}\end{array}$ & $0.8 f_{a}$ & $\frac{0.8 t_{a}}{G_{a}} f_{a}$ & $\frac{1}{3} \delta_{f}$ & $\frac{3 G_{f}}{2 \tau_{f}}+\frac{3}{4} \delta_{0}$ & $\begin{array}{l}\text { Bilinear } \\
\text { model }\end{array}$ \\
\hline
\end{tabular}

\section{Fracture energy}

The fracture energy is directly related to the ultimate failure load of the double-strap joint specimens. It is the area under the bond-slip curve that represents the ultimate bond strength. The associated fracture energy for double lap joint can be calculated using the 
following equation, which can be used to predict the interfacial fracture energy of the bonded CFRP to the base material.

$$
G_{f}=\frac{P_{u}^{2}}{2 b_{p}^{2} E_{p} t_{p}}
$$

where $\mathrm{P}_{\mathrm{u}}$ is ultimate load, $\mathrm{b}_{\mathrm{p}}$ is the width of the plate, Ep and tp are the elastic modulus and thickness of the plate, respectively, and Gf is the fracture energy of the bonded interface (Batuwitage et al., 2017). It was stated in He and Xian's report that the interfacial fracture energy depended on both the ultimate tensile strain of the adhesive (the elastic/shear modulus for the same tensile strength) and the thickness of adhesive layer.

In the study of Wang and $\mathrm{Wu}$, it was discovered that the experimental interfacial fracture energy for both Araldite 2015 and Sikadur 30 adhesive bonded specimens increases with increasing adhesive thickness (Wang and Wu, 2018). Nonlinear adhesives with a lower elastic modulus but a larger strain capacity is shown to give a much higher interfacial fracture energy than linear adhesives with a similar or even a higher tensile strength (Yu et al., 2012).

\section{Stress-strain modelling}

To investigate the bond relationship between CFRP and steel, the stress-strain behaviour of adhesive double-lap joints need to be analysed. CFRP sheets and CFRP plates are proved to have similar behaviour as bonded to a steel plate double-lap joint (Lam et al., 2007). Since the specimens were subjected to axial tensile load only, it is assumed to have uniform transverse behaviour (Lam et al., 2007).

Hart-smith (Hart-smith, 1973) concluded that a better joint efficiency could be obtained by assigning a suitable adherent thickness ratio and lap length to the joint. Predictions of the joint's maximum axial strength and minimum joint length required can be made from finite element modelling of specimens. The outcomes from analytical analysis can be compared with experimental results to check its validity. The joint's axial load carrying capacity is expected to increase with increasing joint length until it reaches a certain limit. A larger failure deformation could be achieved by increasing joint length past this limit (Lam et al., 2007).

Theoretical model of Hart-Smith is to be applied to obtain estimation on ultimate strength for bond between CFRP plates and steels. Hart-Smith (Hart-smith, 1973) analyzed adhesively bonded double-shear pull test joints to estimate the ultimate bond strength. In the Hart-Smith model, the maximum bond strength for a joint with bond length greater than effective bond length, is given by (Zhao, 2014):

$$
P_{\mathrm{ult}}=b_{\mathrm{CFRP}} \times \min \left(P_{\mathrm{i}}, P_{\mathrm{o}}\right)
$$


where $b_{\mathrm{CFRP}}$ is the width of CFRP, and $P_{\mathrm{i}}$ and $P_{\mathrm{o}}$ are the bond strengths per unit width of the joint:

$$
P_{i}=\sqrt{2 \tau_{f} t_{a}\left(\frac{1}{2} \gamma_{c}+\gamma_{p}\right) 2 E_{\text {steel }} t_{\text {steel }}\left(1+\frac{E_{\text {steel }} t_{\text {steel }}}{2 E_{\text {CFRP }} t_{C F R P}}\right)}
$$

if $E_{\text {steel }} t_{\text {steel }}<2 E_{C F R P} t_{C F R P}$

$$
P_{o}=\sqrt{2 \tau_{f} t_{a}\left(\frac{1}{2} \gamma_{c}+\gamma_{p}\right) 4 E_{\text {steel }} t_{\text {steel }}\left(1+\frac{2 E_{C F R P} t_{C F R P}}{E_{\text {steel }} t_{\text {steel }}}\right)}
$$

if $E_{\text {steel }} t_{\text {steel }} \geq 2 E_{C F R P} t_{C F R P}$

where $E$ is modulus and $\mathrm{t}$ is thickness of CFRP or steel plates, $\tau_{\mathrm{f}}$ is the adhesive shear strength, $\gamma_{\mathrm{c}}\left(=\gamma_{\mathrm{f}} / \mathrm{G}_{\mathrm{a}}\right)$ and $\gamma_{\mathrm{p}}$ are the adhesive elastic and plastic shear strains respectively. $G_{a}$ is the shear modulus of the adhesive, $\gamma_{p}$ can be taken as $3 \gamma_{c}$ for normalmodulus CFRP plate (Liu et al., 2005) and $5 \gamma_{c}$ for high-modulus CFRP plate (Wu et al., 2012a). For the specimens with bond length (L) shorter than effective bond length $\left(L_{c}\right)$, the bond strength can be estimated by

$$
P_{u l t, L<L_{e}}=P_{u l t} \times \frac{L}{L_{e}}
$$

The effective bond length is given by

$$
L_{c}=\frac{P_{u l t}}{2 \tau_{f} b_{C F R P}}+\frac{2}{\lambda}
$$

and $\lambda$ is calculated as

$$
\lambda=\sqrt{\frac{G_{a}}{t_{a}}\left(\frac{1}{E_{C F R P} t_{C F R P}}+\frac{2}{E_{\text {steel }} t_{\text {steel }}}\right)}
$$

\section{Parameters affecting bond performance}

\section{Loading rate}

The effect of loading rate on bond strength between CFRP and steel has been studied in the literature (Al-Zubaidy, Zhao and Al-Mahaidi, 2012). According to that study, the optimum increase in the bond strength is obtained at a loading rate of $3.35 \mathrm{~m} / \mathrm{s}$. The less improvement after the rate of $3.35 \mathrm{~m} / \mathrm{s}$ is due to the occurrence of CFRP delamination within the subsequent CFRP layers which the failure accelerates with increased loading rate. 


\section{Durability}

Durability often considers the ability of one material to resist cracking, oxidation, chemical degradation, delamination and wear for a specific period of time and under a specific environmental condition (Hollaway and Cadei 2002).

According to Batuwitage's research (Batuwitage et al., 2017), degradation of CFRP becomes dominant when CFRP is exposed to accelerated corrosion, resulting in CFRP rupture failure mode. The application of a primer coating prior to installing CFRP is found to be an effective way to enhance the durability and increase load-carrying capacity of double-strap joints. Multi-layer CFRP systems show better durability performance under accelerated corrosive conditions. Double-strap joints show a decrement of deterioration with increased CFRP layers.

\section{Fatigue loading}

Both single-sided and double-sided repairs using composite material of CFRP sheet are studied by Liu, Al-Mahaidi and Zhao. Experimental results show that the application of composite patches substantially reduces crack growth rate and prolong fatigue life. The double-sided repair scheme increased the fatigue life by 2.2-2.7 times over the unpatched steel plates when using normal modulus CFRP sheet. Fatigue life increased by 4.7-7.9 times when applied to high modulus CFRP sheets. The CFRP sheets with high modulus were found to be much more efficient. Bond width has considerable influence on the crack growth life. These two findings were especially true for double-sided repairs. The parameters of patch thickness, patch length and patch configuration, had an influence on fatigue life increase of over $20 \%$ for both single-sided and double-sided repairs (Liu, Al-Mahaidi and Zhao, 2009), except that patch configuration had only a $6 \%$ influence on fatigue life increase for double-sided repairs.

\section{Temperature}

CFRP sheet was found to have an increasing brittleness when temperature decreases (AlShawaf, Al-Mahaidi, and Zhao, 2005). The effect of subzero temperatures (0, -20, and $40^{\circ} \mathrm{C}$ ) on material properties of CFRP and adhesives and the bond behaviour between CFRP and steel were studied by Al-Shawaf, Al-Mahaidi, and Zhao. A normal-modulus CFRP sheet was adopted in the test, with three adhesives being applied and results were compared. It was observed that the ultimate strength, tensile elastic modulus and strain of CFRP sheet are not significantly impacted by change of temperature from $20^{\circ} \mathrm{C}$ to $-40^{\circ} \mathrm{C}$ (Al-Shawaf, Al-Mahaidi, and Zhao, 2005). It was also discovered by Al-Shawaf and Zhao in 2013 that no reduction in bond strength would occur for specimens bonded with Araldite 420 and Sikadur 30, when temperature is subzero up to $-40^{\circ} \mathrm{C}$ (Al-Shawaf and Zhao, 2013).

While subzero temperature was found to have little to no effect on the bond strength, the temperature beyond glass transition temperature $\left(T_{g}\right)$ which is typically between 40 - 
$60^{\circ} \mathrm{C}$, determined to have an influence on bond strength. The bond strength might be significantly reduced when temperature approaches $\mathrm{T}_{\mathrm{g}}$, beyond which the stiffness of the adhesive would reduce (Hollaway and Teng 2008). For temperature lower than $\mathrm{T}_{\mathrm{g}}$, joints will fail by CFRP delamination whereas when temperature higher than $\mathrm{T}_{\mathrm{g}}$, joints will fail by cohesion failure. The difference in failure mode is mainly due to the difference in degradation rate of adhesive layer and CFRP adherend, for which the former is faster than the latter.

\section{Experimental tests}

Experiments are designed to test bond strength of CFRP with HSS/UHSS. According to the manufacturer, CFRP laminates used in this study have nominal Young's modulus of $450 \mathrm{GPa}$ and steel plates are grade 700 (HSS) and grade 1100 (UHSS). A bond length of $330 \mathrm{~mm}$ was adopted in this experiment, and CFRP is bonded with steel plate using Araldite adhesive. The experiment involves three types of configurations: base material (BM) without a CFRP attached as control specimens, single side strengthened (SSS) and double side strengthened (DSS). The schematic view of the specimen is shown in Figure 3. The nominal mechanical properties of CFRP laminates and steel plates are summarized in Table 2.

The surface preparation method has significant impact on the failure modes and tensile capacity of strap joints. The most efficient and economical surface preparation method is found to be sandblasting and surface cleaning using acetone (Batuwitage et al., 2017).

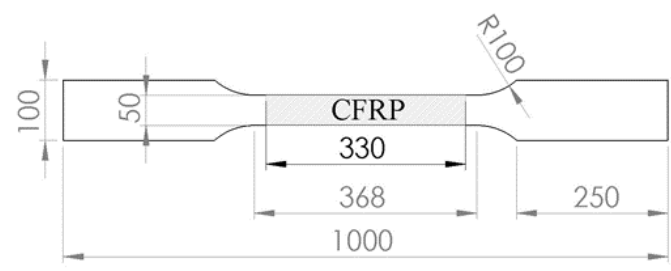

Figure 3. Specimen geometry.

To prepare the Araldite adhesive, small strips of iron wire were cut and mixed in the adhesive mixture. This is to ensure an even thickness of adhesive while minimizing its impact to the overall strength of specimen. The adhesive was then applied onto the steel plate where has been sand blasted and cleaned. Finally, the CFRP plates were then attached and clamped to the steel substrate. Once the specimen is clamped, excessive adhesive would be squeezed out, leaving a uniform layer of adhesive. Specimens were then cured for two weeks to allow adhesive to develop full strength. 
Table 2. Material properties for steel plates.

\begin{tabular}{llll}
\hline & Strenx 700 & Strenx 960 & CFRP \\
\hline Thickness (mm) & 8 & 8 & 2.28 \\
Young's Modulus (GPa) & 200 & 200 & 460 \\
Yield strength (MPa) & 700 & 960 & - \\
Tensile strength (MPa) & $750-950$ & $980-1250$ & 1500 \\
\hline
\end{tabular}

Quasi-static tensile tests were carried out in the displacement control of $1 \mathrm{~mm} / \mathrm{min}$. The load-displacement curves of the specimens are shown in Figure 4. The specimens that are strengthened on one side (SSS) have observed a sudden loss of strength beyond the yield point which was due to the excessive shear stress in the bond.

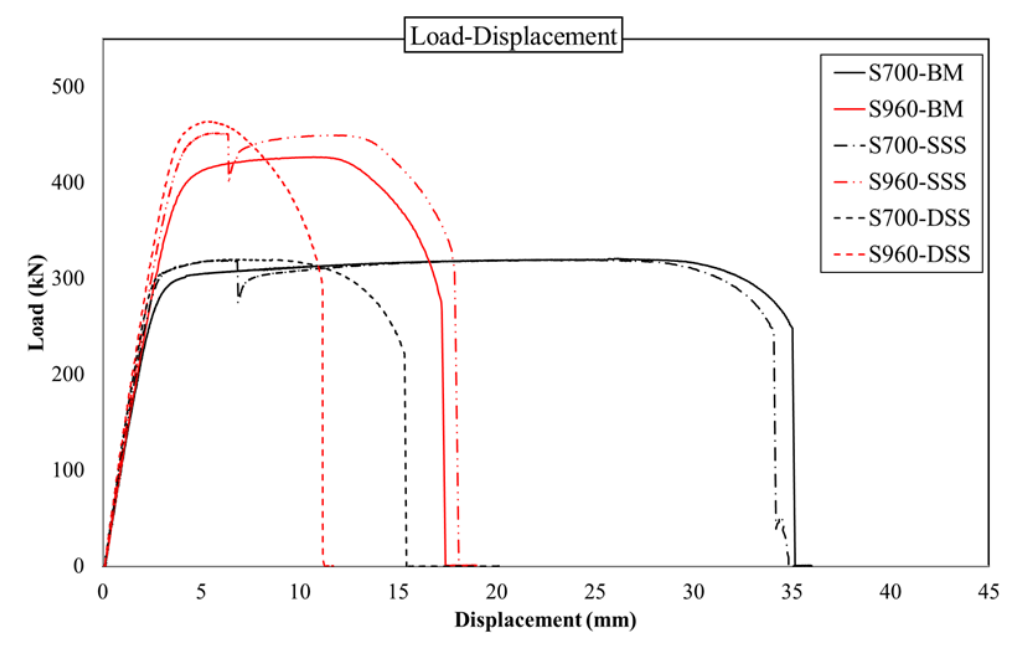

Figure 4. The load-displacement curves of the tested specimens.

Once reached the ultimate load, BM and SSS experiences similar elongation until failure. The DSS specimen has less ductility compared to the BM and SSS. This is due to plastic strain localization at the both ends of the gauge area. The strain change was monitored using DIC technique and outcome is simulated as shown in Figure 5. From the Aramis result, it can be observed that for both steel grade specimens, SSS tend to experience greater strain along the bond length. 


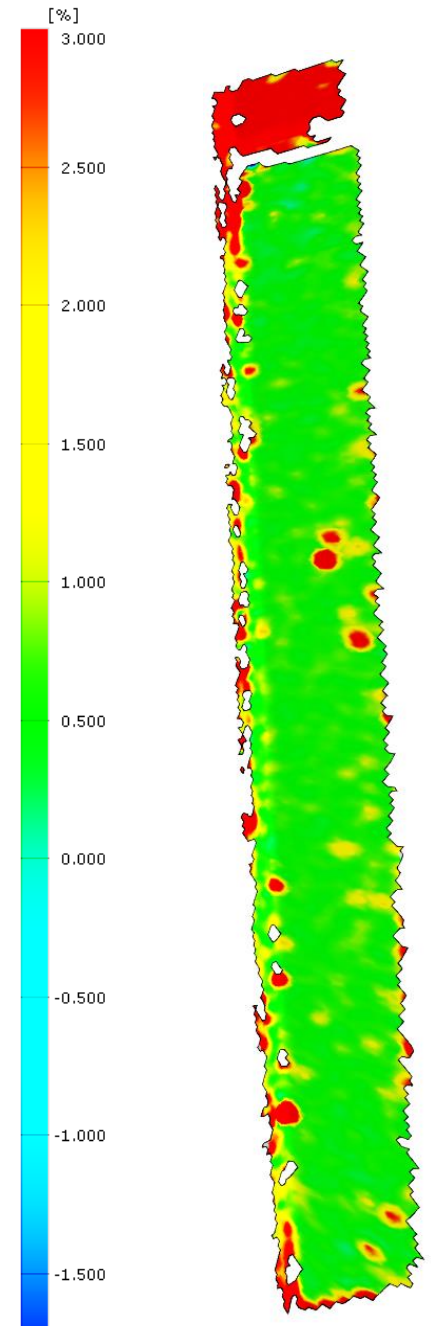

SSS

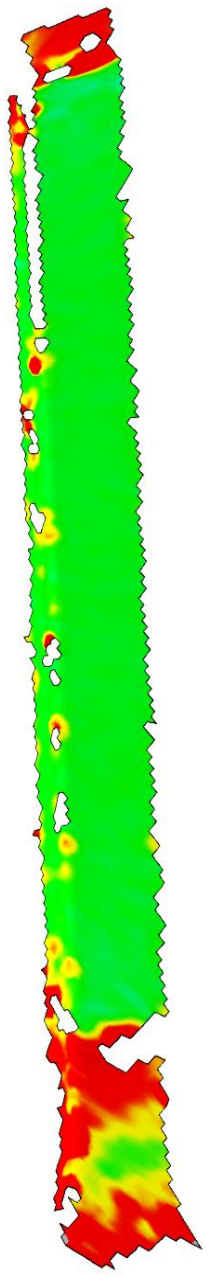

DSS

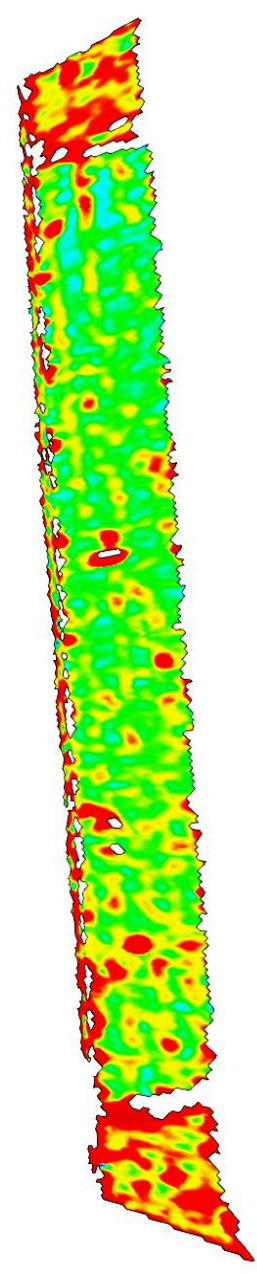

SSS

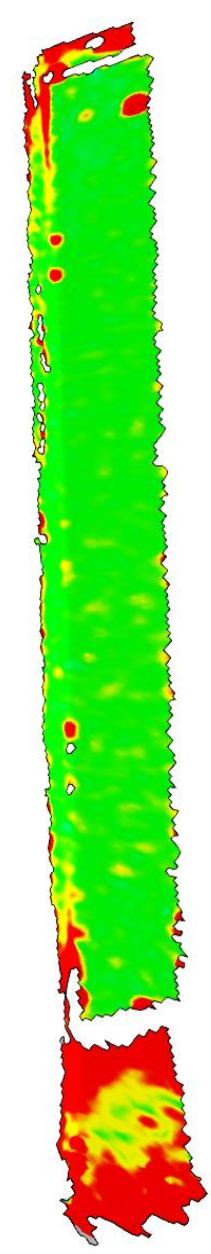

DSS

Figure 5. Strain distribution on the strengthened specimens at the debonding point.

According to Yu's study, bond strength of a CFRP-to-steel bonded joint increases with the plate axial rigidity, provided that failure occurs within the adhesive (i.e. cohesion failure) (Yu et al., 2012). This is proven to be true in this study when S960 specimen has a higher ultimate strength than S700 for SSS specimens. For S960 specimens, adhesive failure is observed in SSS. For DSS specimens, failure mode is seen as steel yielding following by steel rupture. CFRP reinforcement on two sides stiffens the specimen. 


\section{Conclusion}

The bond behavior of ultra-high modulus CFRP to HSS/UHSS is examined in this study and the following conclusions are drawn:

- For ultra-high modulus CFRP strengthening $8 \mathrm{~mm}$ thick steel plates, failure mode is dependent on the bonding configuration for both high and ultra-high strength steel. When it is single-side strengthened, adhesive failure occurs; whereas steel yielding and rupture failure was observed for double-side strengthened specimens.

- According to the initial tests, strengthening higher grades of steel using UHM CFRP is feasible. However, further investigations are required especially when the whole gauge length is covered with CFRP.

- It is also recommended to study CFRP strengthening of welded joints made of HSS/UHSS both under static and fatigue loading.

\section{References}

[1] Al-Shawaf, A., Al-Mahaidi, R., and Zhao, X.L. (2005). Tensile properties of CFRP laminates at subzero temperatures. In Proceedings of the Australian Structural Engineering Conference, Newcastle, UK, September 11-14, 1-9.

[2] Al-Shawaf, A., Al-Mahaidi, R., and Zhao, X.L. (2006). Study on bond characteristics of CFRP/steel double-lap shear joints at subzero temperature exposure. In Proceedings of the Third International Conference on FRP Composites in Civil Engineering (CICE 2006), Miami, December 13-15, 71-74.

[3] Al-Shawaf, A., and Zhao, X.L. (2013). Adhesive rheology impact on wet layup CFRP/steel joints' behaviour under infrastructural subzero exposures. Composites Part B: Engineering, 47, 207-219. https://doi.org/10.1016/j.compositesb.2012.11.012

[4] Al-Zubaidy, H., Zhao, X. and Al-Mahaidi, R. (2012). Dynamic bond strength between CFRP sheet and steel. Composite Structures, 94(11), 3258-3270. https://doi.org/10.1016/j.compstruct.2012.04.025

[5] Amraei, M., Jiao, H., Zhao, X-L., Tong, L-E. (2017). Fatigue testing of buttwelded high strength square hollow sections strengthened with CFRP. ThinWalled Structures, 120, 260-268. https://doi.org/10.1016/j.tws.2017.09.004

[6] Batuwitage, C., Fawzia, S., Thambiratnam, D. and Al-Mahaidi, R. (2017). Durability of CFRP strengthened steel plate double-strap joints in accelerated corrosion environments. Composite Structures, 160, 1287-1298. https://doi.org/10.1016/j.compstruct.2016.10.101

[7] Dehghani, E., Daneshjoo, F., Aghakouchak, A. and Khaji, N. (2012). A new bond-slip model for adhesive in CFRP-steel composite systems. Engineering Structures, 34, 447-454. https://doi.org/10.1016/j.engstruct.2011.08.037

[8] Fawzia, S., Zhao, X., Al-Mahaidi, R., \& Rizkalla, S. (2004). Investigation into the bond between CFRP and steel tubes. Science \& Engineering Faculty, 733. https://doi.org/10.1201/9780203970850.ch82 
[9] Fawzia, S., Zhao, X. and Al-Mahaidi, R. (2010). Bond-slip models for double strap joints strengthened by CFRP. Composite Structures, 92(9), 2137-2145. https://doi.org/10.1016/j.compstruct.2009.09.042

[10] Fernando (2010). Bond Behaviour and Debonding Failures in CFRPStrengthened Steel Members. The Hong Kong Polytechnic University.

[11] Hart-Smith. Adhesive-bonded double-lap joints. Technical report NASACR112235. LongBeach, California, USA, Douglas Aircraft Company, 1973.

[12] He, J. and Xian, G. (2016). Debonding of CFRP-to-steel joints with CFRP delamination. Composite Structures, 153, 12-20. https://doi.org/10.1016/j.compstruct.2016.05.100

[13] He, J. and Xian, G. (2017). Bond-slip behavior of fiber reinforced polymer stripssteel interface. Construction and Building Materials, 155, 250-258. https://doi.org/10.1016/j.conbuildmat.2017.08.062

[14] Hollaway, L.C., and Cadei, J. (2002). Progress in the technique of upgrading metallic structures with advanced polymer composites. Progress in Structural Engineering and Materials, 4(2), 131-148. https://doi.org/10.1002/pse.112

[15] Hollaway, L.C., and Teng, J.G. (2008). Strengthening and rehabilitation of civil infrastructures using fibre-reinforced polymer (FRP) composites. Cambridge, England, Woodhead Publishing Limited. ISBN 978-1-84569-448-7

[16] Korayem AH, Li CY, Zhang QH, Zhao XL, Duan WH. (2015). Effect of carbon nanotube modified epoxy adhesive on CFRP-to-steel interface. Compos B Eng; 79:95-104. https://doi.org/10.1016/j.compositesb.2015.03.063

[17] Lam, A., Cheng, J., Yam, M. and Kennedy, G. (2007). Repair of steel structures by bonded carbon fibre reinforced polymer patching: experimental and numerical study of carbon fibre reinforced polymer - steel double-lap joints under tensile loading. Canadian Journal of Civil Engineering, 34(12), 1542-1553. https://doi.org/10.1139/L07-074

[18] Liu, H.B., Zhao, X.L., Al-Mahaidi, R., and Rizkalla, S.H. (2005). Analytical bond models between steel and normal modulus CFRP. In Proceedings of Fourth International Conference on Advances in Steel Structures, Shanghai, China, June 13-15, 1545-1552. https://doi.org/10.1016/B978-008044637-0/50230-4

[19] Liu, H., Al-Mahaidi, R. and Zhao, X. (2009). Experimental study of fatigue crack growth behaviour in adhesively reinforced steel structures. Composite Structures, 90(1), 12-20. https://doi.org/10.1016/j.compstruct.2009.02.016

[20] L.F.M. da Silva, T.N.S.S. Rodrigues, M.A.V. Figueiredo, M.F.S.F. de Moura, J.A.G. Chousal. (2006). Effect of adhesive type and thickness on the lap shear strength. The Journal of Adhesion, 82(11), 1091-115. https://doi.org/10.1080/00218460600948511

[21] Wu, C., Zhao, X.L., Duan, W.H., and Al-Mahaidi, R. (2012a). Bond characteristics between ultra high modulus CFRP laminates and steel. ThinWalled Structures, 51(2), 147-157. https://doi.org/10.1016/j.tws.2011.10.010

[22] Xia, S.H., and Teng, J.G. (2005). Behavior of FRP-to-steel bond joints. In Proceedings of International Symposium on Bond Behaviour of FRP in Structures (BBFS 2005), Hong Kong, December, 419-426. 
[23] Wang, H. and Wu, G. (2018). Bond-slip models for CFRP plates externally bonded to steel substrates. Composite Structures, 184, 1204-1214. https://doi.org/10.1016/j.compstruct.2017.10.033

[24] Yang, Y., Biscaia, H., Chastre, C. and Silva, M. (2017). Bond characteristics of CFRP-to-steel joints. Journal of Constructional Steel Research, 138, 401-419. https://doi.org/10.1016/j.jcsr.2017.08.001

[25] Yu, T., Fernando, D., Teng, J. and Zhao, X. (2012). Experimental study on CFRPto-steel bonded interfaces. Composites Part B: Engineering, 43(5), 2279-2289. https://doi.org/10.1016/j.compositesb.2012.01.024

[26] Zhao, X.L., and Zhang, L. (2007). State-of-the-art review on FRP strengthened steel structures. Engineering Structures, 29(8), 1808-1823. https://doi.org/10.1016/j.engstruct.2006.10.006

[27] Zhao, X. (2014). FRP-Strengthened Metallic Structures. 2017, CRC Press, ISBN: 9781138074330.

Mohsen Amraei, Lingjia Zong

Department of Civil Engineering, Monash University

Clayton, VIC 3168, Melbourne, Australia

mohsen.amraei@monash.edu

ljzon1@student.monash.edu

Antti Ahola, Timo Björk

Laboratory of Steel Structures, LUT University

P.O. Box 20, 53851 Lappeenranta, Finland

antti.ahola@lut.fi

timo.bjork@lut.fi 